Review

\title{
Microbes, Clinical trials, Drug Discovery, and Vaccine Development: The Current Perspectives
}

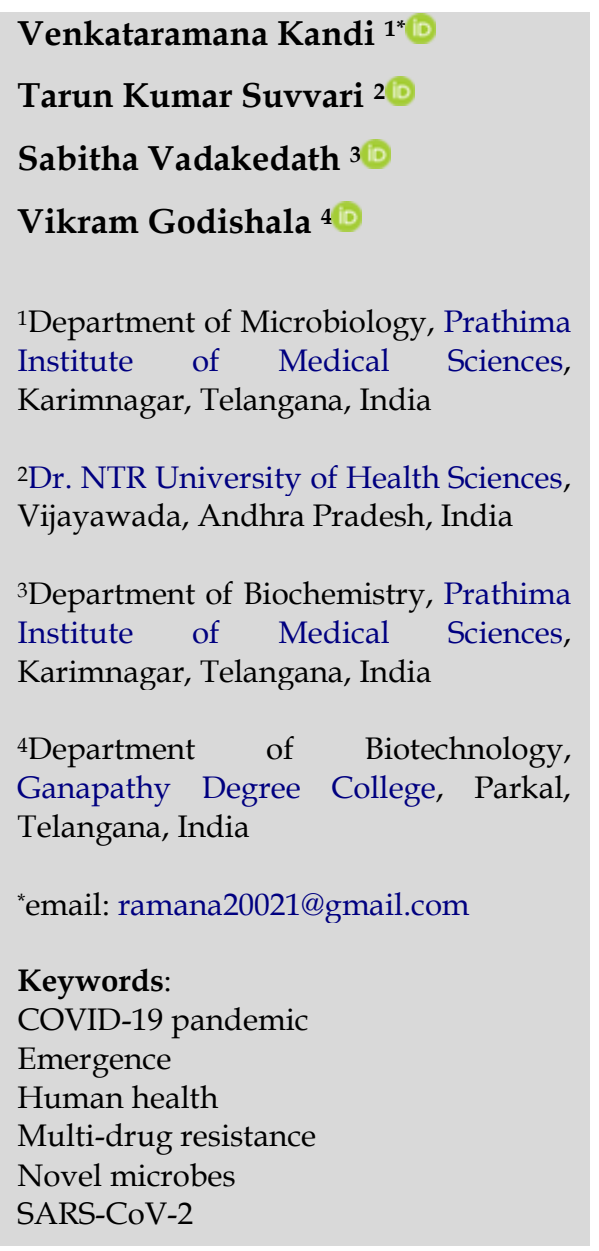

\begin{abstract}
Because of the frequent emergence of novel microbial species and the re-emergence of genetic variants of hitherto known microbes, the global healthcare system, and human health has been thrown into jeopardy. Also, certain microbes that possess the ability to develop multi-drug resistance (MDR) have limited the treatment options in cases of serious infections, and increased hospital and treatment costs, and associated morbidity and mortality. The recent discovery of the novel Coronavirus (n-CoV), the Severe Acute Respiratory Syndrome CoV-2 (SARS-CoV-2) that is causing the CoV Disease-19 (COVID-19) has resulted in severe morbidity and mortality throughout the world affecting normal human lives. The major concern with the current pandemic is the non-availability of specific drugs and an incomplete understanding of the pathobiology of the virus. It is therefore important for pharmaceutical establishments to envisage the discovery of therapeutic interventions and potential vaccines against the novel and MDR microbes. Therefore, this review is attempted to update and explore the current perspectives in microbes, clinical research, drug discovery, and vaccine development to effectively combat the emerging novel and re-emerging genetic variants of microbes.
\end{abstract}

(c) 2021 Venkataramana Kandi, Tarun Kumar Suvvari, Sabitha Vadakedath, Vikram Godishala. Published by Institute for Research and Community Services Universitas Muhammadiyah Palangkaraya. This is an Open Access article under the CC-BY-SA License (http://creativecommons.org/licenses/by-sa/4.0/). DOI: https:// doi.org/10.33084/ bjop.v4i4.2571

Received: August 13th, 2021

Accepted: October 24th, 2021

Published: November 30th, 2021

\section{INTRODUCTION}

The emergence and re-emergence of novel microbial species have always been a challenge to human health ${ }^{1,2}$. This has recently been proven once again with the evolution and spread of hitherto a novel Coronavirus $(\mathrm{CoV})$, which was believed to have emerged and spilled from the bats and pangolins to humans ${ }^{3,4}$. We have noted such microbial emergences previously in the Influenza virus pandemics (1918-America, Europe, Asia), the Human Immunodeficiency Virus (HIV) (1920-
Democratic Republic of Congo (DRC), 1981-America), the Severe Acute Respiratory Syndrome (SARS) CoV (2002), the Middle East Respiratory Syndrome (MERS) CoV (2012), among others. The Dengue virus (1950'sPhilipines, Thailand), Chikungunya virus (1953Tanzania), NIPAH virus (1998-Malaysia), Ebola virus (1976-Central Africa-DRC), Zika virus (1947-East AfricaUganda) are among a few viral species that have shown re-emergence's from time to time, causing endemic and epidemic infections ${ }^{5-8}$. Also, several reports of human 
infections caused by microbes that were previously ignored as non-pathogens ${ }^{9-12}$.

The cause for concern with these microbial emergences is the lack of preparedness among the people, no knowledge of the microbe's pathobiology, and other characteristic features that include the modes of transmission, the severity of infection, and the absence of specific antimicrobial agents or vaccines ${ }^{13}$. Also, it is crucial to understand that humans may not be sufficiently prepared to counter the effects of microbes when encountering novel microbes for the first time ${ }^{14}$. This has been proven from the experiences of the current SARS-CoV-2 pandemic, wherein the initial mortality rates were significantly higher than in the later stages of the pandemic ${ }^{15}$. An increased understanding of the nature of the microbe, its pathobiology is instrumental in exploring the effectiveness of several interventions that include both the repurposed and the novel chemotherapeutic agents on the disease course and help in the development of vaccines ${ }^{16}$. This review focuses on the importance of health and disease, microbes, drug discovery, clinical research, roles of regulatory authorities, and vaccine development.

\section{HEALTH AND DISEASE}

It is important to understand the differences between well-being (healthy) status and the definition/characters of a disease. Also significant is to know what a disease is and the signs and symptoms of a disease. We must understand the mechanism of the disease to identify the areas of interventions to cure/ prevent the disease ${ }^{17}$. New therapies can be helpful when health and disease are understood. Understanding the disease is an important aspect of formulating measures to treat and manage it successfully. As evidenced from a recent research report, framing disease ecosystems (interactions between the human and the disease at the cellular and tissue level) may help us define therapeutic interventions, as illustrated in Figure 1. Some research also highlights the role of diet, age, and sex in disease development ${ }^{18}$. Breaking the human defense barrier and causing disease requires the disturbance of normal homeostasis in various body systems. This is evident from a recent research report that signifies gastrointestinal microbiota's role in maintaining body homeostasis ${ }^{19}$.

In research done on the human immunodeficiency virus (HIV) infected people, it was noted that even though the viral replication was stopped after the initiation of the drug, it could not sustain for a long time after stopping the therapy. This was suspected to be caused by the virus's complex pathophysiology/life cycle, which requires further studies as noted by previous research ${ }^{20}$. There are different therapeutic interventions that a physician chooses to treat a disease/condition. It could vary from a simple drug to a more defined treatment like stem cell transplantation and gene therapy. Several therapeutic interventions that are currently available include pharmaceutical drugs, surgery, transplantations, and molecular/gene therapy. The selection of the best therapeutic intervention depends on the type and nature of the disease, the age, and the pathology of the system involved. Previous research had suggested that in specific cases where gene therapy is the choice of treatment, the early the intervention (in most instances, before even the clinical symptoms start), the best results ${ }^{21}$. Hypertension during pregnancy may lead to several complications in both the mother and the baby. Therefore, managing hypertension among pregnant females assumes greater significance. A sublingual antihypertensive drug that acts fast is usually prescribed among such patients to reduce the complications ${ }^{22}$. In type 1 diabetes, there is a dysfunction of the insulinproducing cells, mostly due to an autoimmune mechanism. Among the various therapeutic 
interventions available, gene therapy appears to be the most advanced type, clearly requiring further research ${ }^{23}$. Therefore, clinical research is of great significance to finding ideas towards identifying and developing newer antimicrobial agents, devices, and drugs.

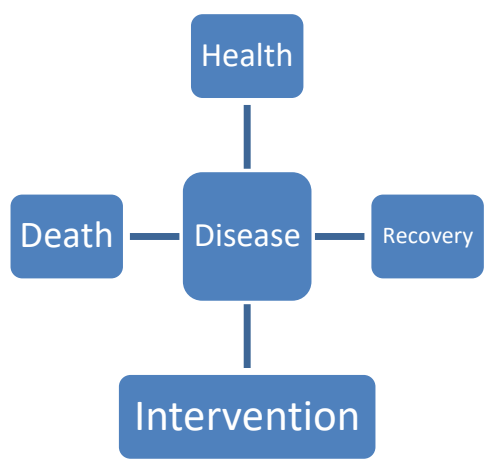

Figure 1. The human health, disease, and their consequence

\section{MICROBES AND DRUG DISCOVERY}

Clinical microbiology involves the study of microbes and the diseases caused by them. Clinical microbiologists focus on the morphology, cultural characters, the pathogenicity-which includes the source of infection and the modes of transmission of the disease, the clinical features that the disease brings about in the infected population, its laboratory diagnosis, and finally, the various methods of therapy and prevention of the disease $^{24}$. While culturing the microbes that cause diseases, it is observed that some microbes require different media/bases/supplements for their culture. Some do not grow in artificial media and may only be maintained in laboratory animals (Leptospira, Mycobacterium leprae, Mycoplasma pneumoniae) $)^{25-27}$. The clinical research knowledge may be used to develop new media to grow such microbes.

Besides pathogenicity, clinical microbiologists understand the life cycles of medically important microbes. This could help perform clinical trials and produce a drug to stop microbial multiplications at various stages of its life cycle and prevent the disease ${ }^{28}$.
The best example is the Human immunodeficiency virus (HIV), for which the antiretroviral drugs were discovered to bisect/stop various stages of its replication ${ }^{29}$.

Laboratory identification methods or devices may be discovered using clinical trial procedures to improve the diagnosis of rare/emerging/existing microbial infectious diseases. Newer antimicrobial agents may be required to treat various microbial infectious diseases that currently have no therapeutic options, like the most common Dengue virus, Chikungunya viral infection, and rare microbes like Zika, Ebola, Nipah virus, and many other microbial infections ${ }^{30,31}$. Currently, we do not have efficient vaccines for several microbial infections for disease prevention. The drug discovery and clinical trials knowledge may be of great use to develop successful vaccines for severe diseases like HIV, Influenza viral infection, Dengue infection, and the emergent novel Coronavirus strains $\mathbf{s}^{32,33}$.

Clinical microbiology involves laboratory work that screens various patients' specimens. Depending on the site of the disease, an appropriate sample is collected if a microbial infection is suspected. For example, someone in the hospital who underwent an operative procedure suffers from post-operative wound infection, and a pus swab is generally collected. This swab is cultured to isolate the bacterium responsible for the infection ${ }^{34}$. Also, we look for the antibiotic sensitivity patterns of the isolated organisms against most of the antibiotics currently used to treat these infections. The cause of concern today is the emergence of antibiotic resistance among microbial species, which limits the treatment options $^{35}$. Another prominent example of antimicrobial resistance is the treatment failures in tuberculosis cases where many tuberculous bacteria resist traditional antitubercular drugs ${ }^{36}$ (Figure 2). 


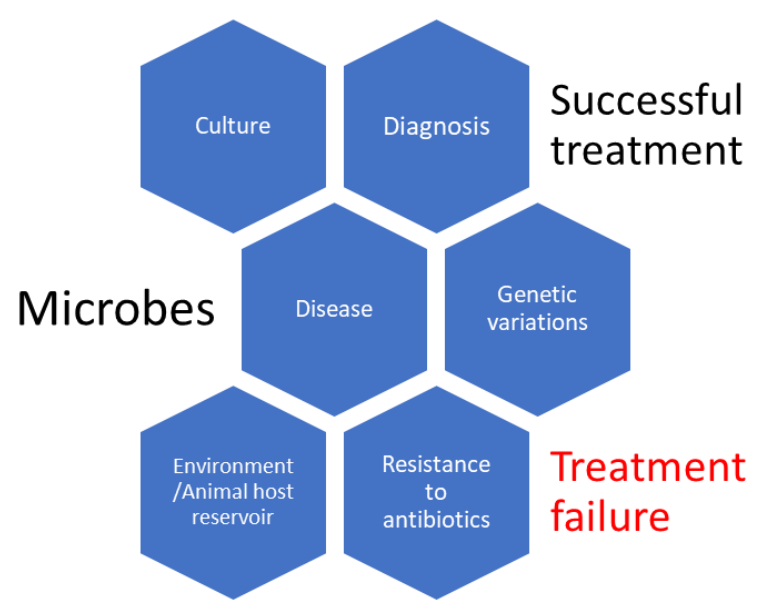

Figure 2. Understanding microbes and their disease consequences

\section{DRUG DISCOVERY AND CLINICAL RESEARCH}

Drugs are not just available, and it requires a considerable effort that involves the biopharmaceutical companies to manufacture them successfully. These companies produce the drugs and market them. All of which fall under the legal aegis of the local and international regulatory authorities. There is an ever-increasing demand for the drugs in the market either due to the increased antimicrobial resistance or the emergence and re-emergence of various microbial infections and other chronic diseases like cancers ${ }^{37}$. We had moved from the times when herbal preparations were used to treat diseases, where the physicians knew that the medicine works (empirical therapy), but they never could know how and why and many other aspects, including the adverse effects. Times have changed now, and biopharmaceutical companies identify the clinical problem, search for a candidate, develop a lead, perform clinical trials, define their pharmacokinetic properties, and do toxicological studies before being approved and used on humans ${ }^{38,39}$.

Developing a new drug and marketing is an uphill task even in the era of advanced technologies. The success of a new drug depends on several factors. One factor that majorly influences the success of a new drug is its performance compared to the standard drug already in use $^{40}$. Also, if it is a therapeutic drug introduced to treat a disease that had no previous treatment, success will depend on the drug's performance based on the phase IV studies (post-marketing analyses) ${ }^{41}$. The pharma companies invest much money to find a drug and hold the patent for the drug if they are successful. Once the patent period expires, the other smaller pharma companies start re-producing and market them in the name of generic drugs ${ }^{42}$. Drug discovery is a process that satisfies the needs of patients, where a new drug is discovered for a known disease that previously had no certified treatment. Drug development also involves the discovery of an alternative drug, which in most instances is superior to the current drug, which is already in use ${ }^{43}$. The drug discovery, development, and commercialization involve the process that includes the identification of a therapeutic concept, selecting a target, its validation, finding a lead compound, its optimization and performing clinical trials, and finally getting its approval for marketing. The drug development process, which is lengthy, complex, and financially expensive, poses a considerable challenge even in automation and technological advancements ${ }^{44}$. A recent research report had highlighted the significance of basic science research in drug discovery and development. This research suggests that the drug development process may be fastforwarded by coordinating the individual laboratory contributions throughout the world in developing a drug target, identifying a target molecule, and performing clinical trials ${ }^{45}$. It may take more than 10-12 years to develop a drug successfully. Most drug discovery research is happening in neurological disorders and cancers $^{46}$. Among the several techniques available for developing a drug, High Throughput Screening (HTS) probably is indispensable ${ }^{47}$. 
Drug discovery is a tedious process wherein most instances, and the candidate drug needs to be obtained from nature ${ }^{48,49}$. To identify the actual molecule with drug capabilities, it must undergo a lengthy process where the lead compound is identified from a raw natural product. The cause of concern is the lengthy and laborious process of drug discovery. Identifying the molecule that possesses the therapeutic effect from raw material is time-consuming. This has been improved with the advent of the high throughput and ultra-high throughput screening techniques 50,51 . A recent research report evidenced by the availability of automation, advanced robotic systems, and software have made the drug development process cost-effective and timeeffective ${ }^{52}$ (Figure 3).

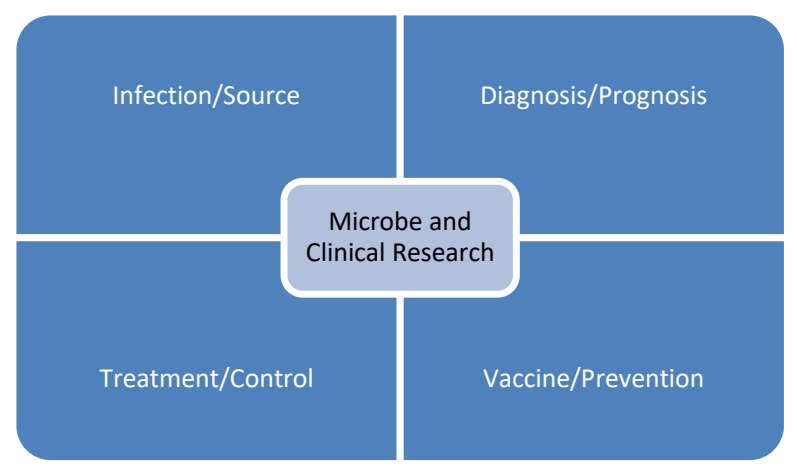

Figure 3. Implications of microbes and clinical research

\section{ROLES OF REGULATORY AUTHORITIES, REGULATIONS, AND GUIDELINES}

A new drug discovery process is almost impossible without good clinical and laboratory practice. The international and national regulatory organizations/agencies like the United States Food, Drug and Cosmetic Act (US-FDA) and the Central Drugs Standards Control Organization (CDSCO), India, play key roles in drug discovery, development, and marketing processes. No research achieves success without following certain principles ${ }^{53}$. Good clinical practice guidelines are available for the laboratories and research personnel. A major part of good clinical practice guidelines includes the ethical aspects of clinical research ${ }^{54}$. Human behavior during clinical research must include six basic principles like autonomy, beneficence, non-maleficence, justice, confidentiality, and honesty ${ }^{55}$. The Nuremberg code was the first of its kind, followed by the World Health Organization's (WHO) 1964 Helsinki declaration, recommending the ethical guidelines throughout the world. The Indian Council for Medical Research (ICMR) guidelines for research, including human subjects, were introduced in 2000 for the first time in India ${ }^{56}$. The whole process of a drug discovery that includes the study design, conduction of the study, its performance, and all other things, including the analysis, auditing, and reporting of the results, comes under an international ethical standard known as good clinical practices (GCP). They basically protect the rights and privileges of the subjects and patients involved in a clinical trial ${ }^{54,57}$.

The GCP has a lengthy historical background wherein the physicians who took the Hippocratic oath, probably the first GCP guideline (460 BC) and followed the rules, were called good physicians. Later, over the years, many other international and national GCP guidelines emerged throughout the world, that include the U.S. Food, Drugs and Cosmetic Act, Nuremberg Code, the Helsinki declaration, the Belmont Report, International Guidelines for Biomedical Research Involving Human Subjects, ICH-GCP guidelines, and the Indian council for medical research (ICMR) guidelines on GCP58. The drug discovery process involves various phases, and the preclinical trials assume increased significance. Here, the in vivo pharmacological and toxicological studies are carried out before a drug is introduced for human use ${ }^{59}$. Although a drug may be exceedingly difficult to discover and may take more than a decade for a potential new drug discovery before it is available in the market, its 
safety to human beings remains paramount. To be called as successful, a newly discovered drug should perform better than the already approved drug in use and be less toxic with minimum or no adverse drug reactions. The final drug approved for human use may be added with the colors, excipients, and other chemicals required for the transport/release/edible of the drug at the target site $^{60}$. A recent report had highlighted the importance of upholding the rights of clinical research participants and the significance of the environmental risk. This report appeals to scientists' cautious approach towards unmeasurable health hazards arising from clinical research activities ${ }^{61}$. The sulphonamide drug deaths due to the excipient diethylene glycol and the more famous thalidomide issue where the antiemetic drug produced teratogenic changes when used during pregnancy give us an idea of the potential complexities involved in clinical research. Such issues can be minimized by better pharmacovigilance ${ }^{62}$ (Figure 4).

\section{Regulatory bodies}
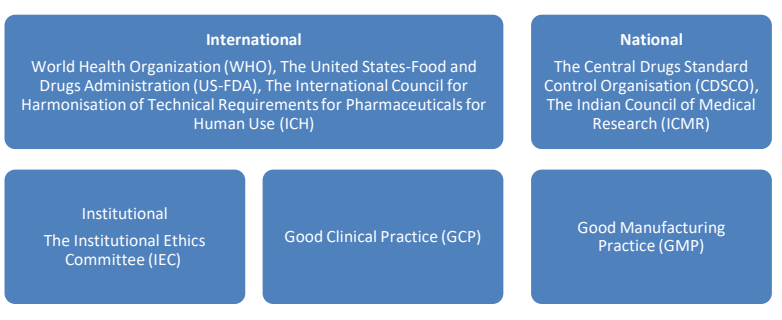

Figure 4. Hierarchy of international and national regulatory authorities

\section{CLINICAL TRIALS FROM DRUG DISCOVERY TO MARKETING}

There are different types of study designs; among them are the types of clinical trials which routinely include human subjects. The core components of clinical trials include the clinical trial personnel's roles and responsibilities, including the regulatory authorities, the clinical research coordinators, and the other persons involved in clinical research like the auditors ${ }^{63}$. Clinical trials are a complex of multiple processes which occur in a sequence and result in the discovery/availability of a new drug. It has four important phases wherein phase 14 involves the human subjects. Phase 1 must be conducted on a select group/cohort of healthy subjects. Furthermore, to describe a healthy subject, one must consider the type of drug to be tested ${ }^{64}$. Alternatively, uniform eligibility may include a human subject with a pulse rate of 50-90 beats per minute as a healthy subject, as reported by a previous study ${ }^{65}$.

Clinical trials are all the procedures done to evaluate the efficacy of a new therapeutic drug candidate/ a medical device. The trials have various phases ranging from phase 0 to phase IV. Phase 0 rarely involves human testing and is done to evaluate the toxicological effects in the lab (in vitro) ${ }^{66}$. Phase I through IV gradually involves new drug testing among healthy/diseased people. The trials mainly constitute the ethical considerations, the study design, application for the investigational new drug (IND), and finally, the new drug application (NDA) after all the phases of clinical trials ${ }^{67}$.

Marketing a pharmaceutical product/drug or a medical device is as important as its discovery. The life cycle of a pharmaceutical product from its discovery, development, and decline is a lengthy process. The drug development process and the marketing of a pharmaceutical product also assume even greater significance, given that it decides its life and success in the market ${ }^{68}$. Several companies produce the exact product/drug in India and are sold in different trade names. This generates a war among the pharma companies, and the marketing of the drugs takes the wrong route by influencing the physicians to prescribe their drug trade name in return for some freebies and other monetary benefits. In countries like India, the 
expensive strategies of drug marketing could contribute to the increased cost of the drug ${ }^{69}$. The pharmaceutical drug marketing happens in phase IV of the clinical trials, where the drug is introduced into the market. Traditionally the "Push technique" was used in drug marketing, where the physicians would recommend a drug. The push technique has been recently replaced by the "pull strategy," where public advertisements are displayed $^{70}$. It was found that the medical representatives' feedback information could influence the physicians' prescription patterns in developed compared to developing nations ${ }^{71}$.

Although a drug is discovered and may finally pass all the trials to reach human usage, it must be made edible by preparing formulations. These formulations are designed to define the drug dosage and the route of administration. A drug approved for humans must be prepared based on the dosage, route of administration, the dosage forms, the edible formulations, and the excipients used to deliver ${ }^{72}$. In recent times we have seen the emergence of nanoparticles as a method of drug preparation and delivery ${ }^{73,74}$. Nanoemulsions use water in oil or oil in water mixed with amphiphilic surfactant holding the drug for effective delivery ${ }^{75}$. The drug discovery and how a drug is prepared (solid/gel/liquid/vapors) for its introduction into a patient also assume greater significance. The drugs may be either solids or liquid forms, depending on their chemical nature. Also, there may be controlled-release preparations and the newest forms like nanoparticles, encapsulated forms, hot-melt extrusions, injection moldings, and many others ${ }^{76}$. The major drawback of many new drug formulations is their low water solubility. This was corrected using a technique called insoluble drug delivery ${ }^{77}$ (Figure 5).

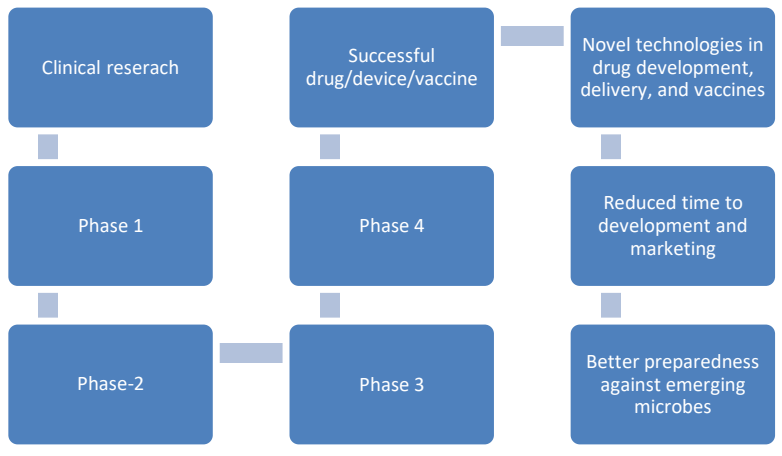

Figure 5. Clinical trial/research process

\section{VACCINE DEVELOPMENT STRATEGIES TO COMBAT INFECTIONS}

Despite the advancement in scientific technologies, we have not been able to develop efficient vaccines against the most common infectious diseases like Malaria, Dengue hemorrhagic fever, Epstein-Barr virus (EBV), Hepatitis C virus (HCV), Herpes Simplex Virus (HSV), and several other bacterial parasitic, viral, and fungal diseases of extreme public health concern. The failure to develop vaccines against several microbes' creeps for various reasons. The ability of microbes to frequently alter their genetic makeup to evade immune responses has been the most significant obstacle for developing effective drugs and vaccines ${ }^{78}$. Previous malaria vaccine studies have also noted that the vaccine, although efficient in eliciting a robust immune response, was not enough to provide long-lasting immunity. This was attributed to parasites' immune-evasive characteristics, which could be countered by instituting immunomodulatory interventions, which are unfortunately not cost-effective in production and administration ${ }^{7989}$.

Scientists have explored the viral vector-associated malaria vaccine and adjuvant-based vaccines (RTS,S/AS01 malaria vaccine) as alternate technologies that can induce Thymus ( $\mathrm{T}$ cell) mediated immune responses, giving better protection against repeated 
Malaria infections ${ }^{82,83}$. Vaccines have proven to be remarkably beneficial in eradicating and controlling various microbial infections like the smallpox virus, poliovirus, Measles, Mumps, and Rubella virus, tuberculosis, diphtheria, pertussis, and tetanus. The major hurdles in developing vaccines against common microbial infections are the complex microbial biology, no commercial drive, and microbes are more prevalent in low socio-economic and third world countries. Infections usually cause no mortality and the time and expenses associated with the development of vaccines ${ }^{78}$ (Figure 6).

\section{Vaccine development strategies}

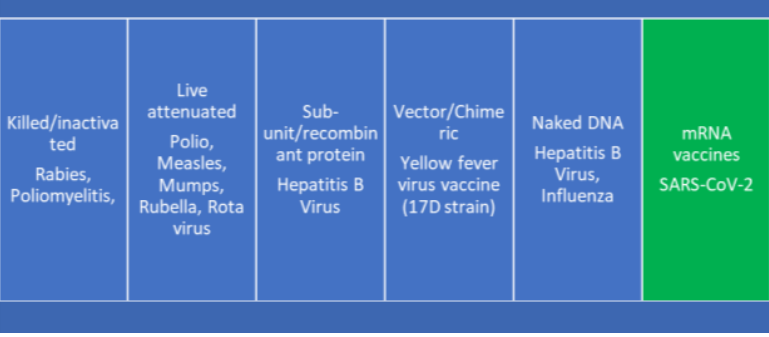

Figure 6. Vaccine development strategies

\section{MESSENGER RIBONUCLEIC ACID (mRNA) VACCINES}

The in vitro transcribed mRNA vaccine is a novel vaccine development strategy, an alternative to the established technologies that have been explored for its use against parasitic infections even before the emergence of the SARS-CoV-2 ${ }^{84}$. The mRNA vaccine technology uses the RNA consisting of genes coding for single or multiple antigens of the infectious agents. Being novel and least explored technology, there is not enough evidence of its efficacy and clarity regarding regulatory requirements. These mRNA's (non-self-replicating) need a vehicle/carrier to be delivered into the cells and are considered safe because they do not integrate with the host's DNA to enable protein synthesis like protein-based DNA vaccines. The idea of self-amplifying mRNAs was also explored to counter the effects of carrier molecules. Also, it was noted that integration of mRNA segments into a carrier RNA virus could result in improved and long-lasting microbial protein synthesis, thereby ensuring effective cellular and antibody (humoral) based immune responses. The success of mRNA vaccines dramatically depends on the quality and purity of the transcripts. Synthesis of such mRNA transcripts uses traditional technologies like UV spectroscopy, fluorescent-based assay, electrophoresis, chromatography, reverse transcription, western blot, and capping RNA at 5' end. The mRNA vaccine candidates are tested for their efficacy using in vitro translational studies, cell-based systems (dendritic and other defensive cells like the antigen-presenting cells), and cell cultures ${ }^{85-}$ 87.

The mRNA vaccine technology is being used for the first time against viral infection with SARS-CoV-2. The first mRNA vaccine went into phase 1 trial in the USA. It is a lipid nanoparticle encapsulated mRNA vaccine named mRNA-127388. The other similar mRNA candidate vaccine againstSARS-CoV-2 is BNT162 a1, b1, b2, and c2, developed by BioNTech, Fosun Pharma, and Pfizer. The vector (Adenovirus, Pox) incorporated mRNA vaccines like ChAdOx1 nCoV-19 (Oxford University, and AstraZeneca), Gam-COVID-Vac Lyo (Gamaleya Institute, Russia), and Ad5-nCoV (CanSino biological, China) have completed phase 3 of vaccine trials and are being cleared by the regulatory authorities for human vaccinations ${ }^{89}$. Some potential disadvantages noted with mRNA vaccine technology include lack of long-term efficacy/protection, degradation of mRNA, toxicity related to the delivery systems, persistent and abnormal stimulation of immunity. The advantages of this technology over the established ones include engineered mRNAs with high immunogenicity (both cellular and antibody responses), no risk of integrating with host 
DNA, no infection risk, and can be produced on large scales at a reasonable time. Other significant concerns with the mRNA vaccine technology are mRNA's unstable nature and temperature sensitivity ${ }^{90}$.

\section{CONCLUSION}

The emergence of novel microbes does not come as a surprise to humankind. The microbial emergences happen naturally and are very tough to predict. The history shows evidence of several emergences and reemergences of microbes. The previous emergences were considered more devastating due to the increased mortality and the non-availability of antimicrobial agents, effective technologies, and infrastructure. Although the current COVID-19 pandemic has come at a time of sophistication, it has still proven to be equally and more devastating than the previous pandemics regarding morbidity and mortality. This results from the increased world population, globalization, inadequate pharmaceutical production capabilities, stringent regulatory guidelines, and under-preparedness. Clinical research enables us to combat diseases and helps us to develop novel, better, and efficient drugs, devices, and vaccines. The improved technological advances should be applied for better preparedness against emergent microbes in the future.

\section{ACKNOWLEDGMENT}

None.

\section{AUTHORS' CONTRIBUTION}

All authors contribute equally.

\section{DATA AVAILABILITY}

Not applicable.

\section{CONFLICT OF INTEREST}

There are no conflicts of interest.

\section{REFERENCES}

1. Kandi V. Coronavirus Disease (COVID-19)/SARSCoV-2: Hopefully, the Human-Virus Battle Ends Soon on a Positive Note. Perspect Clin Res. 2020;8(1):1-3.

2. Pal M, Berhanu G, Desalegn C, Kandi V. Severe Acute Respiratory Syndrome Coronavirus-2 (SARSCoV-2): An Update. Cureus. 2020;12(3):e7423. doi:10.7759/cureus.7423

3. Mahal A, Duan M, Zinad DS, Mohapatra RK, Obaidullah AJ, Wei $X$, et al. Recent progress in chemical approaches for the development of novel neuraminidase inhibitors. RSC Adv. 2021;11(3):180440. doi:10.1039/D0RA07283D

4. Mohapatra RK, Pintilie L, Kandi V, Sarangi AK, Das $\mathrm{D}$, Sahu R, et al. The recent challenges of highly contagious COVID-19, causing respiratory infections: Symptoms, diagnosis, transmission, possible vaccines, animal models, and immunotherapy. Chem Biol Drug Des. 2020;96(5):1187-208. doi:10.1111/cbdd.13761

5. Gubler DJ, Vasilakis N, Musso D. History and Emergence of Zika Virus. J Infect Dis. 2017;216(Suppl_10):S860-S867. doi:10.1093/infdis/jix451

6. Bhatti $A B$, Usman M, Kandi V. Current Scenario of HIV/AIDS, Treatment Options, and Major Challenges with Compliance to Antiretroviral Therapy. Cureus. 2016;8(3):e515. doi:10.7759/cureus.515

7. Ramana KV, Prakash GK. Mystery behind emergence and re-emergence of Chikungunya virus. Ann Trop Med Public Health. 2009;2(1):1-3.

8. Ramana KV. Dengue Viral Infection: Focus on Epidemiology, Laboratory Diagnosis, Management and Control Measures. J Appl Environ Microbiol. 2014;2(5):249-52. doi:10.12691/jaem-2-5-8

9. Bottone EJ. Bacillus cereus, a Volatile Human Pathogen. Clin Microbiol Rev. 2010;23(2):382-98. doi:10.1128/CMR.00073-09 
10. Aslam B, Wang W, Arshad MI, Khurshid M, Muzammil S, Rasool MH, et al. Antibiotic resistance: a rundown of a global crisis. Infect Drug Resist. 2018;11:1645-58. doi:10.2147/IDR.S173867

11. Kandi V. Tungiasis Presenting as Onychomycosis: Probably the First Report of Flea Infestation of the Nail Observed Using Modified Potassium Hydroxide Mount Technique. Cureus. 2018;10(3):e2278. doi:10.7759/cureus.2278

12. Kandi V, Vaish R, Palange P, Bhoomagiri MR. Chronic Pulmonary Histoplasmosis and its Clinical Significance: an Under-reported Systemic Fungal Disease. Cureus. 2016;8(8):e751. doi:10.7759/cureus.751

13. Prestinaci F, Pezzotti P, Pantosti A. Antimicrobial resistance: a global multifaceted phenomenon. Pathog Glob Health. 2015;109(7):309-18. doi:10.1179/2047773215Y.0000000030

14. Vadakedath S, Kandi V, Mohapatra RK, Pinnelli VBK, Yegurla RR, Shahapur PR, et al. Immunological aspects and gender bias during respiratory viral infections including novel Coronavirus disease-19 (COVID-19): A scoping review. J Med Virol. 2021;93(9):5295-309. doi:10.1002/jmv.27081

15. Singhal T. A Review of Coronavirus Disease-2019 (COVID-19). Indian J Pediatr. 2020;87(4):281-6. doi:10.1007/s12098-020-03263-6

16. Pulendran $B, A$ hmed R. Immunological mechanisms of vaccination. Nat Immunol. 2011;12(6):509-17. doi:10.1038/ni.2039

17. Svastalog AL, Doney D, Kristoffersen NJ, Gajovic S. Concepts and definitions of health and health-related values in the knowledge landscapes of the digital society. Croat Med J. 2017;58(6):431-5. doi:10.3325/cmj.2017.58.431

18. Hochberg ME. An ecosystem framework for understanding and treating disease. Evol Med Public Health. 2018;2018(1):270-86. doi:10.1093/emph/eoy032

19. De Sordi L, Lourenço M, Debarbieux L. The Battle Within: Interactions of Bacteriophages and Bacteria in the Gastrointestinal Tract. Cell Host Microbe. 2019;25(2):210-8. doi:10.1016/j.chom.2019.01.018

20. Chun TW, Moir S, Fauci AS. HIV reservoirs as obstacles and opportunities for an HIV cure. Nat Immunol. 2015;16(6):584-9. doi:10.1038/ni.3152
21. Gray SJ. Timing of Gene Therapy Interventions: The Earlier, the Better. Mol Ther. 2016;24(6):1017-8. doi:10.1038/mt.2016.20

22. von Dadelszen P, Magee LA. Preventing deaths due to the hypertensive disorders of pregnancy. Best Pract Res Clin Obstet Gynaecol. 2016;36:83-102. doi:10.1016/j.bpobgyn.2016.05.005

23. Atkinson MA, von Herrath M, Powers AC, ClareSalzler M. Current Concepts on the Pathogenesis of Type 1 Diabetes-Considerations for Attempts to Prevent and Reverse the Disease. Diabetes Care. 2015;38(6):979-88. doi:10.2337/dc15-0144

24. Rhoads DD, Sintchenko V, Rauch CA, Pantanowitz L. Clinical Microbiology Informatics. Clin Microbiol Rev. 2014;27(4):1025-47. doi:10.1128/CMR.00049-14

25. Samrot AV, Sean TC, Bhavya KS, Sahithya CS, ChanDrasekaran S, Palanisamy R, et al. Diagnosis-A Review. Pathogens. 2021;10(2):145. doi:10.3390/pathogens10020145

26. Tanigawa K, Hayashi Y, Hama K, Yamashita A, Yokoyama K, Luo Y, et al. Mycobacterium leprae promotes triacylglycerol de novo synthesis through induction of GPAT3 expression in human premonocytic THP-1 cells. PLoS One. 2021;16(3):e0249184.

doi:10.1371/journal.pone.0249184

27. Gaspari E, Malachowski A, Garcia-Morales L, Burgos R, Serrano L, dos Santos VAPM, et al. Model-driven design allows growth of Mycoplasma pneumoniae on serum-free media. NPJ Syst Biol Appl. 2020;6:33. doi:10.1038/s41540-020-00153-7

28. How KY, Song KP, Chan KG. Porphyromonas gingivalis: An Overview of Periodontopathic Pathogen below the Gum Line. Front Microbiol. 2016;7:53. doi:10.3389/fmicb.2016.00053

29. Tseng A, Seet J, Phillips EJ. The evolution of three decades of antiretroviral therapy: challenges, triumphs and the promise of the future. Br J Clin Pharmacol. 2015;79(2):182-94. doi:10.1111/bcp.12403

30. Oliver GF, Carr JM, Smith JR. Emerging infectious uveitis: Chikungunya, dengue, Zika and Ebola: A review. Clin Exp Ophthalmol. 2019;47(3):372-80. doi:10.1111/ceo.13450

31. Raina SK. State of the Globe: Human Nipah Virus Infection needs "One Health". J Glob Infect Dis. 2020;12(1):1-2. doi:10.4103/jgid.jgid_155_19 
32. Bos S, Gadea G, Despres P. Dengue: a growing threat requiring vaccine development for disease prevention. Pathog Glob Health. 2018;112(6):294-305. doi:10.1080/20477724.2018.1514136

33. Wolf J, Bruno S, Eichberg M, Jannat R, Ruso S, VanRheenenS, et al. Applying lessons from the Ebola vaccine experience for SARS-CoV-2 and other epidemic pathogens. NPJ Vaccines. 2020;5:51. doi:10.1038/s41541-020-0204-7

34. Miller JM, Binnicker MJ, Campbell S, Carroll KC, Chapin KC, Gilligan PH, et al. A Guide to Utilization of the Microbiology Laboratory for Diagnosis of Infectious Diseases: 2018 Update by the Infectious Diseases Society of America and the American Society for Microbiology. Clin Infect Dis. 2018;67(6):e1-e94. doi:10.1093/cid/ciy381

35. Munita JM, Arias CA. Mechanisms of Antibiotic Resistance. Microbiol Spectr. 2016;4(2):15. doi:10.1128/microbiolspec.VMBF-0016-2015

36. Zhang MW, Zhou L, Zhang Y, Chen B, Peng Y, Wang F, et al. Treatment outcomes of patients with multidrug and extensively drug-resistant tuberculosis in Zhejiang, China. Eur J Med Res. 2021;26:31. doi:10.1186/s40001-021-00502-0

37. Kesik-Brodacka M. Progress in biopharmaceutical development. Biotechnol Appl Biochem. 2018;65(3):306-22. doi:10.1002/bab.1617

38. Taylor D. The Pharmaceutical Industry and the Future of Drug Development. In: Pharmaceuticals in the Environment. London (UK): The Royal Society of Chemistry; 2015. p. 1-33. doi:10.1039/978178262234500001

39. Ho CH, Yi J, Wang X. Biocatalytic Continuous Manufacturing of Diabetes Drug: Plantwide Process Modeling, Optimization, and Environmental and Economic Analysis. ACS Sustain Chem Eng. 2019;7(1):1038-51.

doi:10.1021/acssuschemeng.8b04673

40. Wouters OJ, McKee M, Luyten J. Estimated Research and Development Investment Needed to Bring a New Medicine to Market, 2009-2018. JAMA. 2020;323(9):844-53. doi:10.1001/jama.2020.1166

41. Wong $\mathrm{CH}$, Siah KW. Estimation of clinical trial success rates and related parameters. Biostatistics. 2019;20(2):273-86. doi:10.1093/biostatistics/kxx069
42. Gurgula O. Strategic Patenting by Pharmaceutical Companies - Should Competition Law Intervene? IIC Int Rev Ind Prop Copyr Law. 2020;51:1062-85. doi:10.1007/s40319-020-00985-0

43. Katiyar C, Gupta A, Kanjilal S, Katiyar S. Drug discovery from plant sources: An integrated approach. Ayu. 2012;33(1):10-9. doi:10.4103/09748520.100295

44. Hughes JP, Rees S, Kalindjian SB, Philpott KL. Principles of early drug discovery. Br J Pharmacol. 2011;162(6):1239-49. doi:10.1111/j.14765381.2010.01127.x

45. Mohs RC, Greig NH. Drug discovery and development: Role of basic biological research. Alzheimers Dement. 2017;3(4):651-7. doi:10.1016/j.trci.2017.10.005

46. Kaitin KI. Deconstructing the Drug Development Process: The New Face of Innovation. Clin Pharmacol Ther. 2010;87(3):3556-61. doi:10.1038/clpt.2009.293

47. Dahlin JL, Walters MA. The essential roles of chemistry in high-throughput screening triage. Future Med Chem. 2014;6(11):1265-90. doi:10.4155/fmc.14.60

48. Paul D, Sanap G, Shenoy S, Kalyane D, Kalia K, Tekade RK. Artificial intelligence in drug discovery and development. Drug Discov Today. 2021;26(1):8093. doi:10.1016/j.drudis.2020.10.010

49. Dugger SA, Platt A, Goldstein DB. Drug development in the era of precision medicine. Nat Rev Drug Discov. 2018;17(3):183-96. doi:10.1038/nrd.2017.226

50. Pradhan S, Sinha C. Sulfonamide derivatives as Mycobacterium tuberculosis inhibitors: in silico approach. In Silico Pharmacol. 2018;6:4. doi:10.1007/s40203-018-0041-9

51. Szymański P, Markowicz M, Mikiciuk-Olasik E. Adaptation of high-throughput screening in drug discovery-toxicological screening tests. Int J Mol Sci. 2012;13(1):427-52. doi:10.3390/ijms13010427

52. Prabhu GRD, Urban PL. The dawn of unmanned analytical laboratories. Trends Anal Chem. 2017;88:41-52. doi:10.1016/j.trac.2016.12.011

53. Lee SL, Saluja B, Garcia-Arieta A, Santos GML, Li Y, LuS, et al. Regulatory Considerations for Approval of Generic Inhalation Drug Products in the US, EU, 
Brazil, China, and India. AAPS J. 2015;17(5):1285-304. doi:10.1208/s12248-015-9787-8

54. Vijayanathan A, Nawawi O. The importance of Good Clinical Practice guidelines and its role in clinical trials. Biomed Imaging Interv J. 2008;4(1):e5. doi:10.2349/biij.4.1.e5

55. Das NK, Sil A. Evolution of Ethics in Clinical Research and Ethics Committee. Indian J Dermatol. 2017;62(4):373-9. doi:10.4103/ijd.ijd_271_17

56. Sanmukhani J, Tripathi CB. Ethics in Clinical Research: The Indian Perspective. Indian J Pharm Sci. 2011;73(2):125-30. doi:10.4103/0250-474x.91564

57. Kartoğlu Ü,Siagian RC, Reeves TC. Creating a “Good Clinical Practices Inspection" Authentic Online Learning Environment through Educational Design Research. TechTrends. 2020;64;616-27. doi:10.1007/s11528-020-00509-0

58. Imran M, Samad S, Maaz M, Qadeer A, Najmi AK, Aqil M. Hippocratic oath and conversion of ethicoregulatory aspects onto doctors as a physician, private individual and a clinical investigator. J Midlife Health. 2013;4(4):203-9. doi:10.4103/09767800.122232

59. Issa NT, Wathieu H, Ojo A, Byers SW, Dakshanamurthy S. Drug Metabolism in Preclinical Drug Development: A Survey of the Discovery Process, Toxicology, and Computational Tools. Curr Drug Metab. 2017;18(6):556-65. doi:10.2174/1389200218666170316093301

60. Lautié E, Russo O, Ducrot P, Boutin JA. Unraveling Plant Natural Chemical Diversity for Drug Discovery Purposes. Front Pharmacol. 2020;11:397. doi:10.3389/fphar.2020.00397

61. Aschner M, Autrup HN, Bery SCL, Boobis AR, Cohen SM, Creppy EE, et al. environmental risk assessments and regulations. Toxicology. 2016;371:12-6. doi:10.1016/j.tox.2016.09.005

62. Alshammari TM. Drug safety: The concept, inception and its importance in patients' health. Saudi Pharm J. 2016;24(4):405-12. doi:10.1016/j.jsps.2014.04.008

63. Chan AW, Tetzlaff JM, Gøtzsche PC, Altman DG, Mann H, Berlin JA, et al. SPIRIT 2013 explanation and elaboration: guidance for protocols of clinical trials. BMJ. 2013;346:e7586. doi:10.1136/bmj.e7586
64. Singh K, Mehta S. The clinical development process for a novel preventive vaccine: An overview. J Postgrad Med. 2016;62(1):4-11. doi:10.4103/00223859.173187

65. Breithaupt-Groegler K, Coch C, Coenen M, Donath F, Erb-Zohar K, Francke K, et al. Who is a 'healthy subject'?-consensus results on pivotal eligibility criteria for clinical trials. Eur J Clin Pharmacol. 2017;73:409-16. doi:10.1007/s00228-016-2189-8

66. Burt T, Young G, Lee W, Kusuhara H, Langer O, Rowland M, Sugiyama Y. Phase 0/microdosing approaches: time for mainstream application in drug development? Nat Rev Drug Discov. 2020;19:801-18. doi:10.1038/s41573-020-0080-x

67. Umscheid CA, Margolis DJ, Grossman CE. Key concepts of clinical trials: a narrative review. Postgrad Med. 2011;123(5):194-204. doi:10.3810/pgm.2011.09.2475

68. Katsanis LP, Pitta D. Managing the risk aspects of the product development process at the Upjohn Company. J Prod Brand Manag. 2006;15(4):250-4. doi:10.1108/10610420610679610

69. Narendran R, Narendranathan M. Influence of pharmaceutical marketing on prescription practices of physicians. J Indian Med Assoc. 2013;111(1):47-50.

70. Parker RS, Pettijohn CE. Pharmaceutical drug marketing strategies and tactics: a comparative analysis of attitudes held by pharmaceutical representatives and physicians. Health Mark Q. 2005;22(4):27-43. doi:10.1300/j026v22n02_03

71. Murshid MA, Mohaidin Z. A systematic review of the influence of medical representatives and promotional tools on prescribing: A comparison between developed and developing countries. Int J Pharm Healthc Mark. 2017;11(4):361-94. doi:10.1108/IJPHM-09-2016-0047

72. Palcsó B, Zelkó R. Different types, applications and limits of enabling excipients of pharmaceutical dosage forms. Drug Discov Today Technol. 2018;27:21-39. doi:10.1016/j.ddtec.2018.04.002

73. Kumar M, Bishnoi RS, Shukla AK, Jain CP. Techniques for Formulation of Nanoemulsion Drug Delivery System: A Review. Prev Nutr Food Sci. 2019;24(3):225-34. doi:10.3746/pnf.2019.24.3.225

74. Kandi V, Kandi S. Antimicrobial properties of nanomolecules: potential candidates as antibiotics in 
the era of multi-drug resistance. Epidemiol Health. 2015;37:e2015020. doi:10.4178/epih/e2015020

75. Singh Y, Meher JG, Raval K, Khan FA, Chaurasia M, Kain NK, et al. Nanoemulsion: Concepts, development and applications in drug delivery. J Control 2017;252:28-49. doi:10.1016/j.jconrel.2017.03.008

76. Erfle P, Riewe J, Bunjes H, Dietzel A. Stabilized Production of Lipid Nanoparticles of Tunable Size in Taylor Flow Glass Devices with High-SurfaceQuality 3D Microchannels. Micromachines. 2019;10(4):220. doi:10.3390/mi10040220

77. Kalepu S, Nekkanti V. Insoluble drug delivery strategies: review of recent advances and business prospects. Acta Pharm Sin B. 2015;5(5):442-53. doi:10.1016/j.apsb.2015.07.003

78. Wykes MN. Why haven't we made an efficacious vaccine for malaria? EMBO Rep. 2013;14(8):661. doi:10.1038/embor.2013.103

79. Mordmüller B, Surat G, Lagler H, Chakravarty S, Ishizuka AS, Lalremruata A, et al. Sterile protection against human malaria by chemoattenuated PfSPZ vaccine. Nature. 2017;542(7642):445-9. doi:10.1038/nature21060

80. Long CA, Zavala F. Malaria vaccines and human immune responses. Curr Opin Microbiol. 2016;32:96102. doi:10.1016/j.mib.2016.04.006

81. McCall MBB, Kremsner PG, Mordmüller B. Correlating efficacy and immunogenicity in malaria vaccine trials. Semin Immunol. 2018;39:52-64. doi:10.1016/j.smim.2018.08.002

82. Bliss CM, Drammeh A, Bowyer G, Sanou GS, Jagne YJ, Ouedraogo O, et al. Viral Vector Malaria Vaccines Induce High-Level T Cell and Antibody Responses in West African Children and Infants. Mol Ther. 2017;25(2):547-59. doi:10.1016/j.ymthe.2016.11.003

83. Pallikkuth S, Chaudhury S, Lu P, Pan L, Jongert E, Wille-Reece $U$, et al. A delayed fractionated dose RTS,S AS01 vaccine regimen mediates protection via improved $\mathrm{T}$ follicular helper and $\mathrm{B}$ cell responses. eLife. 2020;9:e51889. doi:10.7554/eLife.51889

84. Versteeg L, Almutairi MM, Hotez PJ, Pollet J. Enlisting the mRNA Vaccine Platform to Combat Parasitic Infections. Vaccines. 2019;7(4):122. doi:10.3390/vaccines7040122
85. Dai L, Gao GF. Viral targets for vaccines against COVID-19. Nat Rev Immunol. 2021;21(2):73-82. doi:10.1038/s41577-020-00480-0

86. Vitiello A, Ferrara F. Brief review of the mRNA vaccines COVID-19. Inflammopharmacology. 2021;29(3):645-9. doi:10.1007/s10787-021-00811-0

87. Poveda C, Biter AB, Bottazzi ME, Strych U. Establishing Preferred Product Characterization for the Evaluation of RNA Vaccine Antigens. Vaccines. 2019;7(4):131. doi:10.3390/vaccines7040131

88. Baden LR, El Sahly HM, Essink B, Kotloff K, Frey S, Novak R, et al. Efficacy and Safety of the mRNA-1273 SARS-CoV-2 Vaccine. N Engl J Med. 2021;384:403-16. doi:10.1056/NEJMoa2035389

89. Malik JA, Mulla AH, Farooqi T, Pottoo FH, Anwar S, Rengasamy KRR. Targets and strategies for vaccine development against SARS-CoV-2. Biomed Pharmacother. 2021;137:111254. doi:10.1016/j.biopha.2021.111254

90. Wang F, Kream RM, Stefano GB. An Evidence Based Perspective on mRNA-SARS-CoV-2 Vaccine Development. Med Sci Monit. 2020;26:e924700. doi:10.12659/msm.924700 